\title{
Antifungal activity of a recombinant defensin CADEF1 produced by Escherichia coli
}

\author{
Dahui Li $\cdot$ Jianzhong Li
}

Received: 10 February 2009/ Accepted: 10 June 2009/Published online: 5 July 2009

(C) Springer Science+Business Media B.V. 2009

\begin{abstract}
The defensin CADEF1 has been known to be uptranscripted in the pepper Capsicum anпиит L., upon bacterial attack, abiotic elicitors and environmental stresses. However, the native form of CADEF1 has not been purified from the pepper, and its activity against fungi has been uncertain. In this study, the full-length cDNA of CADEF1 was obtained by fragment piecing-together method. Thereafter, its mature peptide coding sequence was inserted into bacterial expression vector pET28a(+), and the recombinant vector was transformed into Escherichia coli BL21 (DE3). Based on SDS-PAGE and Western blotting analysis, the recombinant CADEF1 was produced as a $5.6 \mathrm{kDa}$ protein in the form of inclusion body in E. coli BL21 (DE3) and the expression level accounted for $15 \%$ of the bacterial total protein. Further processing through protein refolding and purification, converted the inclusion body type of CADEF1 into active form with the yield about $13 \mu \mathrm{g} / \mathrm{ml}$ of culture. The refolded CADEF1 significantly showed the activity against growth of the fungal pathogen Verticillium dahliae on average by $67.9 \%$ in vitro assay. These results verified the novel activity of CADEF1, which might benefit in prevention of the fungus-related disease in agricultural production.
\end{abstract}

Keywords Antifungal activity - Bacterial expression . Defensin · Verticillium dahliae

\footnotetext{
D. Li $\cdot$ J. Li (ه)
}

Department of Environmental Biotechnology, Research Center for Eco-Environmental Sciences, Chinese Academy of Sciences, Shuangqing Road No. 18, Haidian District, 100085 Beijing, China

e-mail: jzhongli@yahoo.com.cn

\section{Introduction}

Defensins are a cysteine-rich protease with antimicrobial activity (Broekaert et al. 1995). Originated from a variety of organisms including animals, plants, inserts and mammals, defensins exhibit structural similarities: (1) lowmolecular-weight peptides with 45-54 amino acids, and (2) cysteine-rich with two to six disulphide bridges (GarciaOlmedo et al. 1999; Thomma et al. 2002). Plants defensins, in particularly, display a specific eight-cysteine arrangement that is related with stabilization of their particular globular structures, and consist of a signal peptide domain to target the protein for extracellular secretion and a mature peptides domain to exhibit biological activity (Broekaert et al. 1997).

Plant defensins have initially been identified in seeds (Terras et al. 1995), and recently been reported in other plant organs and tissues, e.g., leaves, flower, fruit, pods and tubers (Stiekema et al. 1988; Chiang and Hadwiger 1991; Meyer et al. 1996; Urdangarin et al. 2000). They play a significant role in host defense. Moreover, recombinant defensin production in yeast or transgenic plants, has well displayed activities against various plant pathogens. rDFN1, a defensin in bark and fruit tissues of peach, has been produced in functional form in the yeast Pichia pastoris, and the activity assay in vitro showed that the recombinant defensin could inhibit germination of the fungal pathogens Penicillium expansum and Botrytis cinerea (Wisniewski et al. 2003). The transgenic tobacco plants with radish defensin showed an enhancement of resistance to the foliar fungal pathogen Alternaria longipes (Terras et al. 1995). And expression of the defensin from Medicago sativa in transgenic potato plants provided robust resistance to pathogen Verticillium dahliae (Gao et al. 2000). These evidences suggest that molecular 
cloning and expression of the specific defensin through genetic engineering, should open opportunities with regards to utilization of defensins for prevention of certain fungal diseases in agricultural production.

CADEF1 was a defensin from the pepper (Capsicum annиum L.) and its expression was up-transcripted in response to bacterial attack, abiotic elicitors and environmental stresses (Do et al. 2004). However, the native form of CADEF1 has not been purified from the pepper, and there are no reports up to date on whether it has inhibitive activity against fungi or not. In this work, the full-length cDNA of CADEF1 was cloned by fragment piecing-together method, according to its sequence in Genbank with accession number AF442388, and subsequently expressed in Escherichia coli. Cloning of the cDNA and construction of the bacterial expression system would provide a recombinant CADEF1 protein, which is required for its in vitro assay of the antifungal activity. The aims of this study were: (1) to determine the utility of recombinant technology to produce the therapeutic protein CADEF1 in E. coli, and (2) to verify its antifungal activity of the cloned bacterial products.

\section{Materials and methods}

Bacterial strains, plasmids and fungal strain

Escherichia coli DH5 $\alpha$ and plasmid pMD18-T (TaKaRa, Japan) were used for DNA manipulation. E. coli BL21 (DE3) and plasmid pET28a(+) (Novagen, Germany) were used for expression of CADEF1 gene. Fungal strain $V$. dahliae Kleb. was obtained from the Institute of Plant Protection, Chinese Academy of Agricultural Sciences.

\section{Cloning of full-length CADEF1 cDNA}

Ten oligonucleotide fragments (Table 1) were designed and synthesized based on the sequence of CADEF1 cDNA
(Genbank accession number AF442388). After phosphorylation at their $5^{\prime}$ terminal, fragments LF1-LF8 (100 nmol, respectively) were mixed together, then denatured at $90^{\circ} \mathrm{C}$ for $2 \mathrm{~min}$ and at $80^{\circ} \mathrm{C}$ for $5 \mathrm{~min}$. The mixture was kept at $50^{\circ} \mathrm{C}$ for $10 \mathrm{~min}$, then at room temperature by gradually decreasing in temperature. Followed by ligation at $16^{\circ} \mathrm{C}$ overnight with T4 DNA ligase (TaKaRa, Japan), the mixture was finally used for PCR with fragments fullP1 and fullP2 as primers. The PCR reaction was done over 35 cycles of denaturation for $30 \mathrm{~s}$ at $94^{\circ} \mathrm{C}$, annealing for $45 \mathrm{~s}$ at $55^{\circ} \mathrm{C}$, extension for $45 \mathrm{~s}$ at $72^{\circ} \mathrm{C}$, and finally for $10 \mathrm{~min}$ extension at $72^{\circ} \mathrm{C}$. The PCR system without the template was used as negative control. After PCR, the resulting products were run in $1.5 \%$ agarose gels, and the band of interest was eluted and purified with a PCR Fragment Recovery Kit (TaKaRa, Japan). The purified fragment was further cloned into pMD18-T vector. The sequence of the clone was confirmed by DNA sequencing (Shanghai Bioeng, China).

Construction of bacterial expression vector pET28a-CADEF1

To obtain clones merely with the mature peptide coding region of CADEF1, a primer, called matP1 with EcoRI site (5'-GAGAATTCAGAACTTGCGAGTCG-3'), was designed based on the mature peptide coding sequence of the target clone obtained above. The cDNA fragments of the mature peptide coding region of CADEF1 were amplified using PCR as in the above-mentioned procedure (with matP1 and fullP2 as primers). The amplified product was cloned into pMD18-T, and the recombinant plasmid, pMD18-T-CADEF1, was digested with EcoRI and HindIII. The resulting fragment of CADEF1 was further cloned into the EcoRI and HindIII sites of plasmid pET28a(+). The resultant bacterial expression vector, pET28a-CADEF1, was then transformed into E. coli BL21 (DE3) cells. The empty vector of pET28a(+) was also introduced into BL21 (DE3) as a control.

Table 1 Oligonucleotide fragments used for fragment piecing-together method

\begin{tabular}{lll}
\hline & Sequence $\left(5^{\prime} \rightarrow 3^{\prime}\right)$ & Restriction site \\
\hline fullP1 & GAGAATTCATGGCACACTCCATG & EcoRI \\
fullP2 & CGCAAGCTTTAACATGGCCTAGTG & HindIII \\
LF1 & TCCATGCGTTCTTTGCTATTGTATTGCTTCTAGCAATGCTTGTCATGGCCACTGAG & \\
LF2 & TACCGTGTGAGGTACGCAAAGAAACGATAACATAACGAAGATCGTTACGAACAGTAC \\
LF3 & ATGGGACCAATGAGAATTGTTGAGGCAAGAACTTGCGAGTCGCAGAGCCATCGTTTC \\
LF4 & CGGTGACTCTACCCTGGTTACTCTTAACAACTCCGTTCTTGAACGCTCAGCGTCTCG \\
LF5 & AAGGGAGTATGTGCTAGTGAGACGAATTGTGCCTCCGTCTGTCAGACCGAAGGATTTC \\
LF6 & GTAGCAAAGTTCCCTCATACACGATCACTCTGCTTAACACGGAGGCAGACAGTCTGGCT \\
LF7 & CGGTGGTGATTGCCGTGGATTTCGCCGCCGCTGCTTCTGCACTAGGCCATGTTAA & \\
LF8 & TCCTAAAAGGCCACCACTAACGGCACCTAAAGCGGCGGCGACGAAGACGTGATCC & \\
\hline
\end{tabular}


Recombinant protein production in $E$. coli

Escherichia coli BL21 (DE3) cells containing a plasmid of interest were cultured overnight at $37^{\circ} \mathrm{C}$ in $5 \mathrm{ml}$ LuriaBertani medium containing appropriate antibiotics $(50 \mu \mathrm{g} / \mathrm{ml}$ of kanamycin). The culture obtained was then diluted 1:100 (v/v) into $200 \mathrm{ml}$ of the same medium and allowed to grow at $37^{\circ} \mathrm{C}$ until an optical density of 0.5 at $600 \mathrm{~nm}\left(\mathrm{OD}_{600}\right)$. IPTG (isopropyl $\beta$-D-thiogalactopyranoside) was added to a final concentration of $1.0 \mathrm{mM}$ and cells were grown at 37 or $28^{\circ} \mathrm{C}$ for $5 \mathrm{~h}$.

Refolding and purification of recombinant protein

The IPTG-induced bacterial cells were collected by centrifugation at $12,000 \times \mathrm{g}$ for $10 \mathrm{~min}$ and resuspended in extraction buffer (50 mM Tris- $\mathrm{HCl}$ buffer, $\mathrm{pH} 7.8,2 \mathrm{mM}$ EDTA and $500 \mu \mathrm{g} / \mathrm{ml}$ lysozyme). The expressed proteins were extracted out from the cells by sonication for $5 \mathrm{~min}$ with an interval of $30 \mathrm{~s}$ for every $30 \mathrm{~s}$ sonication at $4^{\circ} \mathrm{C}$. The insoluble lysates (containing inclusion bodies) and supernatant were then separated by centrifugation at $12,000 \times \mathrm{g}$ for $15 \mathrm{~min}$. After the inclusion bodies were dissolved in $8 \mathrm{M}$ urea, containing $50 \mathrm{mM}$ Tris- $\mathrm{HCl}$ buffer (pH 7.8), $1 \mathrm{mM}$ phenylmethylsulfonyl fluoride, and $10 \mathrm{mM}$ dithiothreitol, the resultant supernatant was collected by centrifugation at $12,000 \times g$ for $15 \mathrm{~min}$ and used for protein refolding. Protein refolding was processed at $4^{\circ} \mathrm{C}$ through dialysis against the buffer systems $(50 \mathrm{mM}$ Tris- $\mathrm{HCl}$ buffer, $2 \mathrm{mM}$ glutathione reduced, $1 \mathrm{mM}$ glutathione oxidized, $\mathrm{pH} 7.8$ ), containing $6,4,2,1$ and $0.5 \mathrm{M}$ urea, respectively, to dialyse gradually the concentration of urea in the protein solution, and finally against the same buffer but containing no urea to eliminate the remnant urea. Purification of the refolded protein was carried out according to the ProBond ${ }^{\mathrm{TM}}$ Purification System Kit (Invitrongen, USA) for the recombinant protein tagged with $6 \times$ histidine. The poly-His tag at the $\mathrm{N}$-terminus of the recombinant protein was eliminated by using Thrombin Cleavage Capture Kit (Novagen, Germany), following which the biotinylated thrombin protease was removed. The reaction was kept at $20^{\circ} \mathrm{C}$ for $18 \mathrm{~h}$, in a $400 \mu \mathrm{l}$ buffer system containing $20 \mathrm{mM}$ Tris- $\mathrm{HCl}(\mathrm{pH} 7.8), 150 \mathrm{mM}$ $\mathrm{NaCl}, 2.5 \mathrm{mM} \mathrm{CaCl} 2,100 \mu \mathrm{g}$ recombinant protein and $0.2 \mathrm{U}$ thrombin. Washing of the column with streptavidin agarose was done as recommended by the manufacturer.

Gel scanning analysis, determination of protein concentration and molecular weight

Total protein collected from the above-mentioned processes (i.e., bacterial expression, dissolution of inclusion bodies, protein refolding and purification), was analyzed by
$17.5 \%$ sodium dodecyl sulfate-polyacrylamide gel electrophoresis (SDS-PAGE), and the gel was stained with Coomassie Brilliant Blue. To monitor yield of the recombinant protein, the stained gel was scanned and analyzed by GelDoc2000 system (Bio-Rad, USA). The protein concentration was determined by the Lowry method with bovine serum albumin as standard (Lowry et al. 1951).

The molecular weight of recombinant protein was analyzed using a TofSpec matrix-assisted laser desorption/ ionization time of flight mass spectrometry (MALDI-TOFMS, Micromass, UK) with $\alpha$-cyano-4-hydroxy-transcinnamic acid as the matrix and an accelerating voltage of $20 \mathrm{kV}$.

\section{Western blotting}

For Western blotting, mouse polyclonal antibody against CADEF1, was prepared by injecting the purified protein obtained above into mice according to Sambrook et al. (1989). After SDS-PAGE, proteins were transferred to nitrocellulose membranes. Immunodetection was performed using the mouse polyclonal antibody against CADEF1 at 1:20,000 dilution as primary antibody and alkaline phosphatase-conjugated anti-mouse immunoglobulins as secondary antibody (Promega, USA), followed by employing NBT/BCIP in the phosphatase reaction.

\section{Antifungal activity assay}

Both in vitro methods of plate-based fungal growth inhibition (Fang et al. 2005) and microspectrophotometry (Broekaert et al. 1990) were used for antifungal activity assay. The procedure was as following: (1) V. dahliae was cultured on potato-dextrose-agar (PDA) medium plates at $25^{\circ} \mathrm{C}$ for 3 weeks. (2) For assay by plate-based fungal growth inhibition, its hyphae discs with $10 \mathrm{~mm}$ in diameter were cut off from petri dishes; solution of the refolded CADEF1 was added to PDA medium to produce the PDA plate with final concentration of $400 \mu \mathrm{g} / \mathrm{ml}$; and the $10 \mathrm{~mm}$ hyphae disc was inoculated at $25^{\circ} \mathrm{C}$ on the PDA plate containing the refolded CADEF1. (3) For assay by microspectrophotometry, its spores were washed off from petri dishes with sterile water and collected by centrifugation at $8,000 \times \mathrm{g}$ for $5 \mathrm{~min} ; 200 \mu \mathrm{g}$ of the refolded CADEF1, was added to $500 \mu \mathrm{l}$ suspension of the spores $\left(1 \times 10^{3}\right.$ spores $/ \mathrm{ml}$ Czapek's medium $)$ and co-incubated at $25^{\circ} \mathrm{C}$; absorbency at $595 \mathrm{~nm}\left(\mathrm{OD}_{595}\right)$ was monitored each $12 \mathrm{~h}$ after co-incubation; and the inhibition on the fungal growth was calculated by the formulation: inhibition ratio $(\%)=\left[\left(\mathrm{OD}_{595}\right.\right.$ of negative control- $-\mathrm{OD}_{595}$ of refolded $\mathrm{CADEF} 1) / \mathrm{OD}_{595}$ of negative control] $\times 100$. (4) A further set of $V$. dahliae strain were treated similarly with the unrefolded CADEF1 and the total protein from the 
bacterial cell $E$. coli BL21 (DE3) with empty pET28a(+) vector, as negative controls, respectively.

For investigation on conditions of the in vitro antifungal activity assay, a series of tests with the refolded CADEF1 at different concentration $(150,200,250,300,350,400,450$ and $500 \mu \mathrm{g} / \mathrm{ml})$ and incubation temperature $(18,25$ and $32^{\circ} \mathrm{C}$ ) were carried out as described above, respectively.

\section{Results}

Cloning of the full-length and the mature peptide coding region of CADEF1 cDNA

By PCR with the designed primers, a cDNA fragment with the size of $\sim 237 \mathrm{bp}$ was obtained (Fig. 1). This result was consistent with the open reading frame sequence of CADEF1 gene, which encodes a polypeptide of 78 amino acids consisting of a predicted signal peptide of 31 amino acids at the $\mathrm{N}$-terminus domain and a mature peptide of 47 amino acids with calculated molecular mass of $5.6 \mathrm{kDa}$ (Do et al. 2004). Upon PCR amplification with two primers, matP1 and fullP2, only the mature peptide coding region of CADEF1 cDNA was cloned, showing a product of the expected size (144 bp) in an agarose gel (Fig. 2). The resulting cDNA fragment, corresponding to the mature peptide of CADEF1, was further cloned into pMD18-T, then constructed into expression vector pET28a(+). An

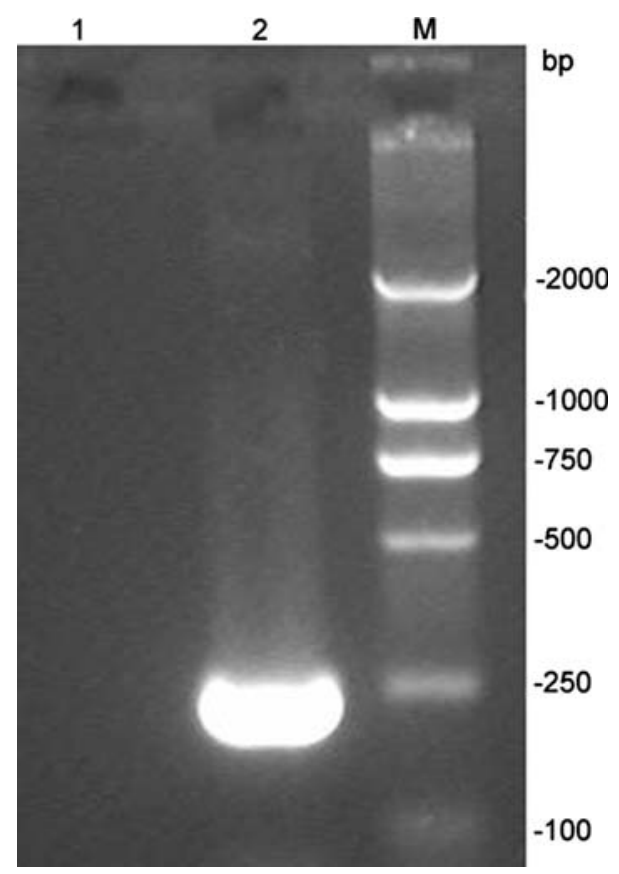

Fig. 1 PCR amplification of the ligation product. Lane 1 negative control; lane 2237 bp product of PCR; lane M DL2000 DNA Marker

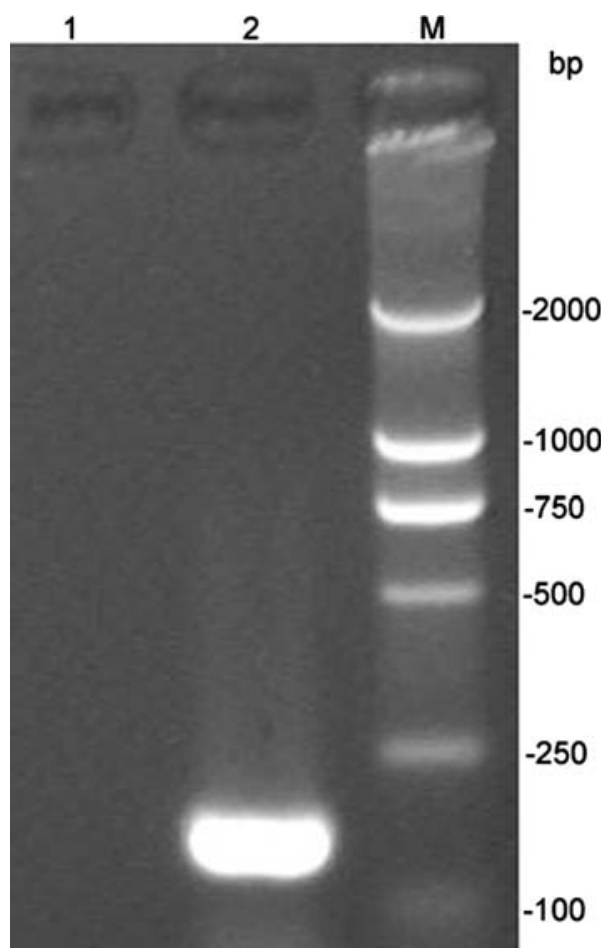

Fig. 2 PCR product of the mature peptide coding region of CADEF1. Lane 1 negative control; lane $2144 \mathrm{bp}$ product of PCR; lane M DL2000 DNA Marker

EcoRI and HindIII digestion was used to screen the recombinant pET28a-CADEF1, which was subsequently transformed into E. coli BL21 (DE3).

\section{Bacterial expression of CADEF1}

After the pET28a-CADEF1 clone was transformed into E. coli system, the expressed recombinant CADEF1 was identified by SDS-PAGE (Fig. 3). Under the condition without IPTG induction, there is no detectable recombinant CADEF1 protein in the bacteria BL21 transformed with pET28a-CADEF1 (Fig. 3, lane 2), as what produced by pET28a $(+)$ vector (negative control, Fig. 3, lane 1). Whereas induced by IPTG at $37^{\circ} \mathrm{C}$, the bacteria BL21 transformed with pET28a-CADEF1 could express recombinant CADEF1 protein (Fig. 3, lane 4). The molecular weight of the expressed recombinant CADEF1 analyzed by MALDI-TOF-MS is $5.6 \mathrm{kDa}$ (Fig. 4). This roughly corresponded to the molecular weight of the predicted mature protein of CADEF1. The amount of the recombinant protein could reach up to about $15 \%$ of BL21 total protein by the gel scanning analysis. When the IPTG-induced bacterial cells were lysated and centrifuged to collect the supernatant and the pellet for SDS-PAGE analysis, respectively, the recombinant CADEF1 protein was found in the insoluble lysates (i.e., inclusion bodies) and accounted for $46.4 \%$ of the total protein in the inclusion 


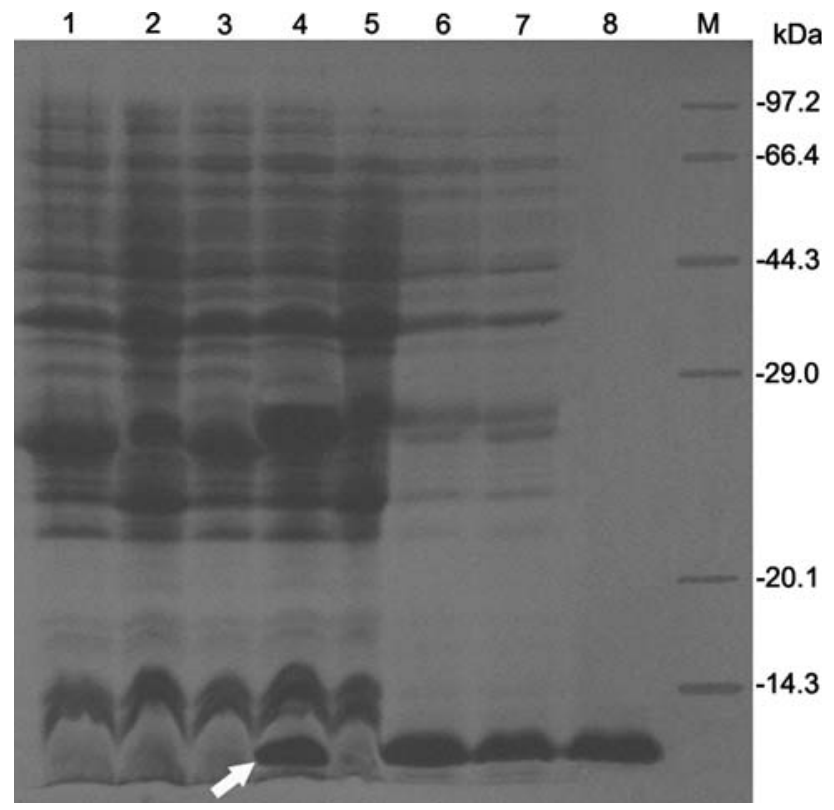

Fig. 3 SDS-PAGE analysis of expressed CADEF1. Expression performed at $37^{\circ} \mathrm{C}$ in E. coli BL21 (DE3). Lane 1 cell fraction of BL21/pET28a(+), by IPTG induction; lane 2 cell fraction of BL21/ pET28a-CADEF1, no IPTG induction; lane 3 soluble lysates from IPTG-induced BL21/pET28a-CADEF1; lane 4 cell fraction of BL21/ pET28a-CADEF1, showing recombinant CADEF1 (arrow), by IPTG induction, and recombinant $\mathrm{CADEF} 1$ was indicated by an arrow; lane 5 cell fraction of BL21/pET28a-CADEF1 including its full length, by IPTG induction; lane 6 inclusion bodies from IPTG-induced BL21/ pET28a-CADEF1, containing recombinant CADEF1; lane 7 protein solution after dialysis and protein refolding; lane 8 purified CADEF1; lane $M$ low molecular mass marker proteins

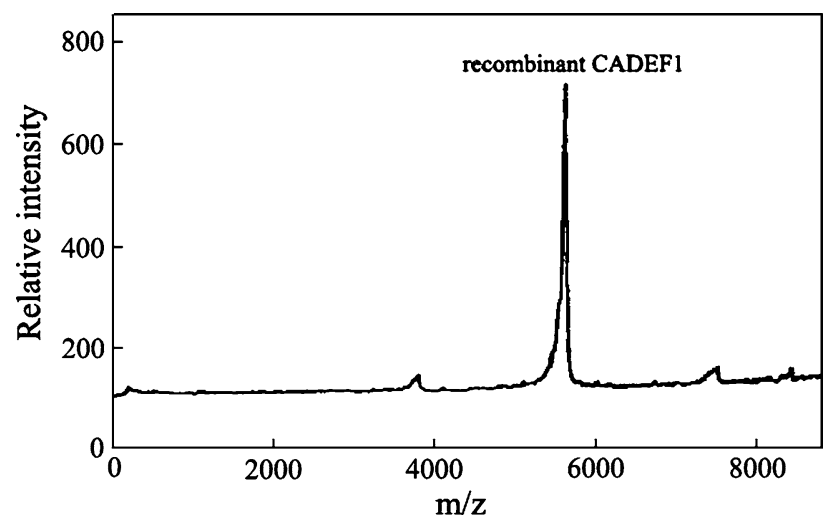

Fig. 4 MALDI-TOF-MS of recombinant CADEF1 using $\alpha$-cyano-4hydroxy-trans-cinnamic acid as the matrix

bodies (Fig. 3, lanes 3, 6). It should be noted that if the fulllength cDNA of CADEF1, including its signal peptide and mature peptide coding sequences, was inserted into pET28a(+) which was then transformed into E. coli BL21 (DE3), no recombinant protein could be induced under the same conditions (Fig. 3, compare lanes 4, 5).

To test the effect of induction temperature on CADEF1 expression in E. coli, we performed the experiments with the same bacterial system but induction at $28^{\circ} \mathrm{C}$. As expected from the results of SDS-PAGE, the expressed CADEF1 showed comparable induction of the bacterial system (data not shown). Although the recombinant protein was still observed in the inclusion bodies, the amount of CADEF1 in this case was about $6 \%$ of BL21 total protein, which was much lower than that induced at $37^{\circ} \mathrm{C}$. These results were consistent with Western blotting detection (Fig. 5). By Western blotting, inclusion body type of the recombinant CADEF1 was detected both at 28 and $37^{\circ} \mathrm{C}$. However, induction at $37^{\circ} \mathrm{C}$ resulted in a significant increase in recombinant CADEF1 as compared to that at $28^{\circ} \mathrm{C}$ (Fig. 5). It correlated well with the gel scanning analysis after SDS-PAGE, demonstrating that the change in the amount of recombinant protein was the result of increased CADEF1 synthesis. Thus the bacterial culture at $37^{\circ} \mathrm{C}$ was used for production of the recombinant protein.

\section{Antifungal activity of CADEF1}

The collected supernatant after inclusion body dissolution, were undertaken for protein refolding. Through protein refolding and purification, purity of the recombinant protein was gradually increased untill over $97 \%$ was achieved (Fig. 3, lanes 7, 8). The final yield of the purified protein was about $13 \mu \mathrm{g} / \mathrm{ml}$ of original bacterial culture. To preliminary evaluate the antifungal activity of the refolded CADEF1 against fungal pathogen $V$. dahliae, the platebased assay was used (Fig. 6). The result showed that both of the unrefolded CADEF1 and total protein from the bacterial cell with empty $\mathrm{pET} 28 \mathrm{a}(+)$ vector haven no activity on inhibition against the fungal growth, which was

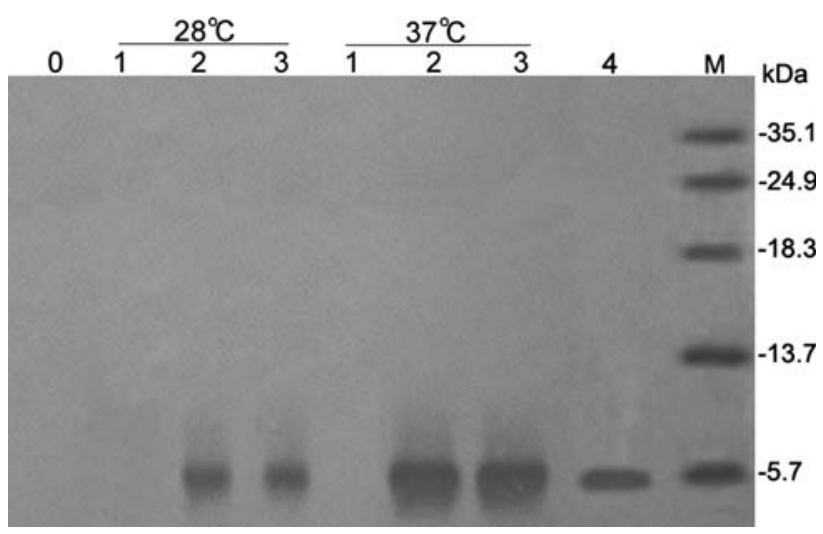

Fig. 5 Effect of induction temperature $\left(28\right.$ or $\left.37^{\circ} \mathrm{C}\right)$ on CADEF1 production in E. coli BL21 (DE3) by anti-CADEF1 Western blotting. Lane $O$ cell fraction of BL21/pET28a-CADEF1, no IPTG induction; lane 1 soluble lysates of BL21/pET28a-CADEF1, by IPTG induction; lane 2 cell fraction of BL21/pET28a-CADEF1, by IPTG induction, and recombinant CADEF1 was indicated by an arrow; lane 3 insoluble lysates of BL21/pET28a-CADEF1, by IPTG induction; lane 4 purified CADEF1; lane $M$ Western blotting marker proteins 
presented by a high dense and thick hyphae disc (Fig. 6a, b). Whereas on the PDA plate with the refolded CADEF1, the growth of the fungal was inhibited, which presented a loose and thin hyphae disc, decreased in diameter with respect to the negative controls (Fig. 6c). When the microspectrophotometry assay was applied to further test the activity of the refolded CADEF1, similar profiles were obtained, in which the refolded CADEF1 showed a strong activity against spores germination and hyphae growth of the fungal pathogen $V$. dahliae (Fig. 7). In presence of the refolded CADEF1 $(400 \mu \mathrm{g} / \mathrm{ml})$, the germination and hyphae growth of $V$. dahliae spores were inhibited, resulting in the sustained lower value of an optical density at $595 \mathrm{~nm}$ and a smooth curve during the period of successive $12 \mathrm{~h}$ incubation (Fig. 7). On the contrary, incubated with the control protein of E. coli BL21 (DE3) or the unrefolded CADEF1, the fungal spores were germinated continuously and the fungal hyphae were grown rapidly, leading to a precipitous increase in turbidity $\left(\mathrm{OD}_{595}\right)$. Calculated with the $\mathrm{OD}_{595}$ value (Fig. 7), the refolded CADEF1 could significantly inhibit the fungal growth on average by $67.9 \%$.

To optimize test conditions of the in vitro assay, one of parameters, i.e., CADEF1 at different concentration or incubation temperature, was altered to determine its effects on antifungal activity against $V$. dahliae. Compared with the negative control protein, there is a dose-dependent response relationship between CADEF1 concentration and inhibition ratio (Fig. 8). The refolded CADEF1 could inhibit the fungal growth with an $\mathrm{EC}_{50}$ (median effective concentration) value of $315.2 \mu \mathrm{g} / \mathrm{ml}$ (Fig. 8). Furthermore, the effect of varying temperature of incubation on antifungal activity was statistically significant in all assay protocols (Fig. 9). As seen in Fig. 9, inhibition ratio of the refolded CADEF1 increased with incubation temperature up to $25^{\circ} \mathrm{C}$ and began to decrease after a $32^{\circ} \mathrm{C}$-incubation.

\section{Discussion}

Transcription of the CADEF1 gene in the pepper C. annuum has been shown to be strongly induced by the strain

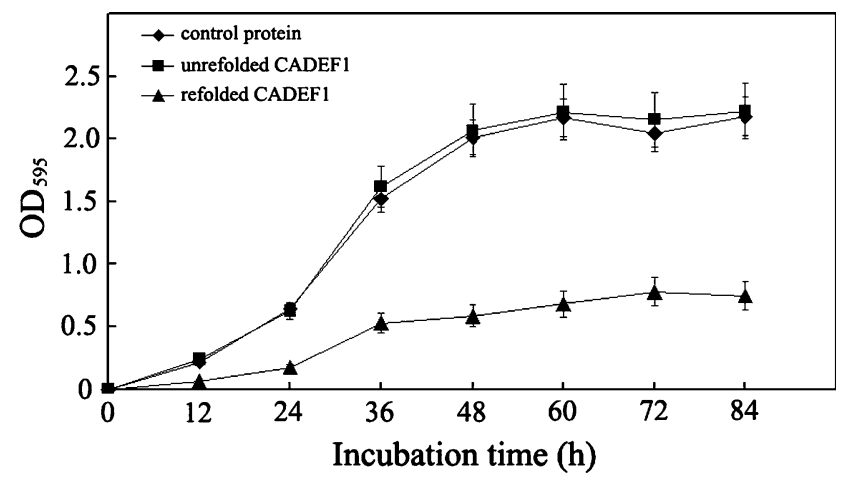

Fig. 7 Antifungal activity of CADEF1 against $V$. dahliae by microspectrophotometry assay. The absorbency at $\mathrm{OD}_{595}$ was monitored at successive $12 \mathrm{~h}$, by co-incubating the fungal spores with the control protein from $E$. coli BL21, the unrefolded CADEF1, and the refolded CADEF1, respectively. The data shown are means ( \pm standard deviation) of three experiments

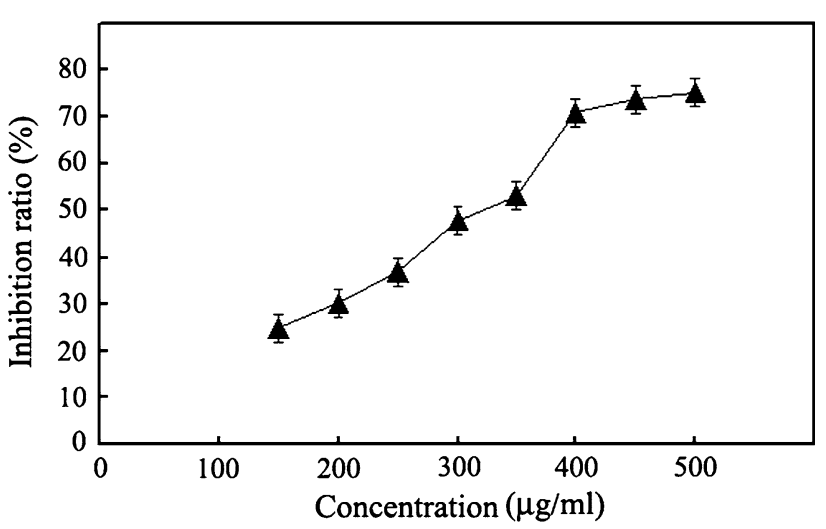

Fig. 8 Inhibition curve of the refolded CADEF1 at different concentration after a $48 \mathrm{~h}$-incubation at $25^{\circ} \mathrm{C}$. The data shown are means ( \pm standard deviation) of three experiments. Regressive equation (calculated by the MS Office Excel 2003) $Y=0.1614 X-0.8738$, correlation coefficient: $0.9659, \mathrm{EC}_{50}: 315.2 \mu \mathrm{g} / \mathrm{ml}$

Xanthomonas campestris pv. vesicatoria, indicating that the defensin is important component of host defense (Do et al. 2004). Since a number of plant defensins has been found to exhibit antifungal activity against a broad range of fungi (Chiang and Hadwiger 1991; Terras et al. 1995; Gao et al. 2000), by analogy, it might be expected that CADEF1
Fig. 6 Antifungal activity of CADEF1 against $V$. dahliae by plate-based assay. $V$. dahliae was inoculated on PDA plates with $400 \mu \mathrm{g} / \mathrm{ml}$ of the control protein from E. coli BL21 (a), the unrefolded CADEF1 (b), and the refolded CADEF1 (c) for 3 days, respectively.

Bars $=10 \mathrm{~mm}$
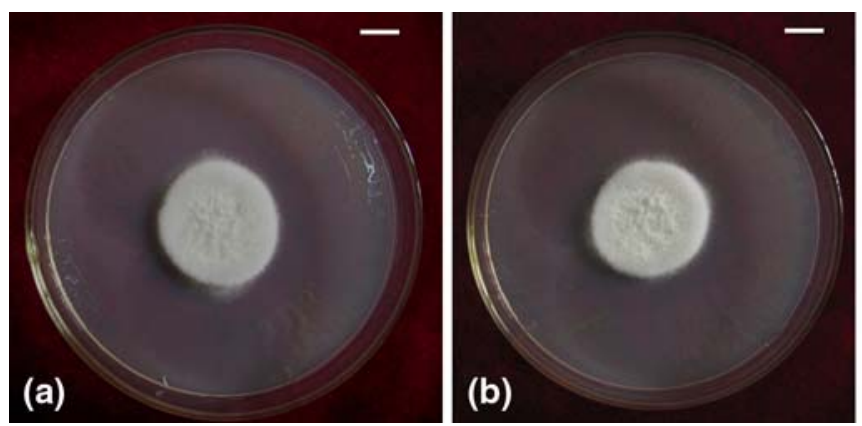


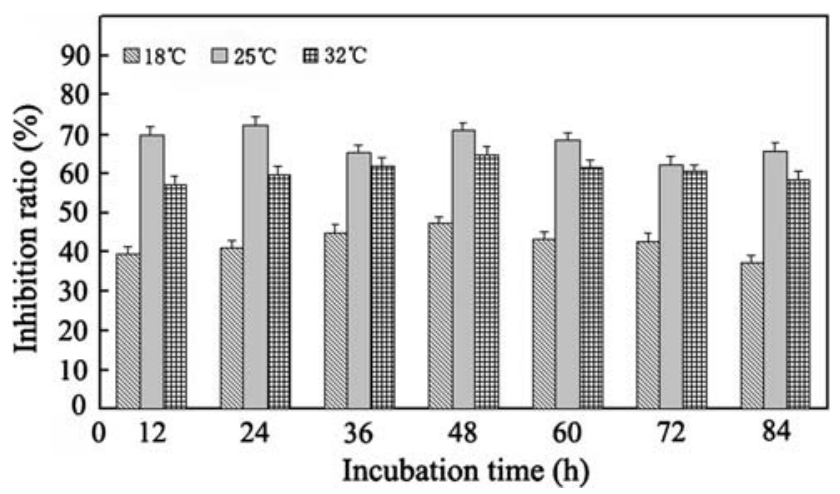

Fig. 9 Effects of incubation temperature $\left(18,25\right.$ and $\left.32^{\circ} \mathrm{C}\right)$ on the inhibition efficiency of the refolded CADEF1 at $400 \mu \mathrm{g} / \mathrm{ml}$. Significant difference $(P<0.05$, by Student's test $)$ was found between higher temperatures $\left(25\right.$ or $\left.32^{\circ} \mathrm{C}\right)$ and lower ones $\left(18^{\circ} \mathrm{C}\right)$ in all protocols. The data shown are means ( \pm standard deviation) of three experiments

should be involved in the similar activity. However, as its mRNA was only expressed at $2 \mathrm{~h}$ after inoculation and gradually reduced by $30 \mathrm{~h}$ (Do et al. 2004), CADEF1 was expressed transiently in the pepper, which made it difficult to be purified in large amounts through biochemical technology. In this work, we have cloned the full-length CADEF1 cDNA and produced mature peptide of CADEF1 as inclusion body type of recombinant protein in bacterial expression system. The recombinant protein in E. coli is suitable to applications in the basic and applied sciences due to its associated simplicity, economic viability, and the large number of genetic strategies available (Sawabe et al. 2007). Compared with other expression system, although yields of correctly folded and functional protein are frequently low due to protein aggregation, E. coli as a host for recombinant protein provides an economic and fast way to produce the molecules in relatively large amounts. The expression level of the recombinant CADEF1 accounted for about $15 \%$ of BL21 total protein, suggesting the expression system is highly efficient. The BL21 bacteria have been induced to produce CADEF1 in similar expression pattern at different temperature, however, the yield of the protein was reduced with the induction temperature decreasing (Fig. 5). Therefore, the IPTG-induction at $37^{\circ} \mathrm{C}$ was adopted to get higher expression level of the protein. The final yield of CADEF1 was $13 \mu \mathrm{g} / \mathrm{ml}$ of original bacterial culture, which was sufficient for its in vitro activity assay. Although not tested, it is convinced that optimizations, in addition to temperature, such as employing other strains and codon optimization should help to enhance this yield.

When the bacterial cells were lysated and centrifuged to collect the soluble and insoluble fractions for SDS-PAGE analysis, respectively, the recombinant CADEF1 protein in large amounts was identified in the insoluble lysates, indicating that it has been expressed in the form of inclusion body (Fig. 3, lane 6). However, an inclusion body type of protein shows no any of biological activity at all (Frankel et al. 1991). In order to convert the inclusion body type of CADEF1 into active forms, protein refolding ensued. Since the protein would be aggregated when the denaturant was suddenly extracted away from the buffer system (Hevehan and Clark 1997), therefore, protein refolding was performed prior to protein purification. During the protein refolding, the concentration of urea was gradually decreased by dialysis, which eventually gave rise to the refolded CADEF1 with antifungal activity (Figs. 6, 7). CADEF1 had the similar antifungal activity at different incubation temperatures in the assay protocols. However, the inhibition ratio of CADEF1 peaked at incubation temperature of $25^{\circ} \mathrm{C}$ (Fig. 9), with maximum inhibition on average by $67.9 \%$. Moreover, the inhibition ratio depended on the CADEF1 concentration used, which showed a dose-response correlation (Fig. 8).

In our separate study, we found that if the full-length cDNA of CADEF1, was inserted into pET28a(+), no recombinant protein could be induced by IPTG under the same conditions (Fig. 3, lane 5). The result obtained in our study correlate well in the case of the bacterial expression of a PR5-like protein from Arabidopsis (Xu and Reddy 1997). In comparison to the results that rDNF1 (a defensin from peach) with or without its signal peptide could be expressed in the yeast, P. pastoris (Wisniewski et al. 2003), we assumed that the E. coli system might not recognize the endogenous signal peptide of the defensin. Moreover, it is known that defensin's prodomain is unnecessary for folding to an active conformation (Broekaert et al. 1997). Thus, we undertook the strategy by which only partial of the CADEF1 cDNA, corresponding to its mature peptide coding sequence, was cloned and subsequently expressed in E. coli expression system.

\section{Conclusions}

By two kinds of in vitro antifungal assays, we concluded that the mature peptide of CADEF1 produced by E. coli, had the significantly activity on inhibition against the fungal pathogen $V$. dahliae which could cause wilt disease of certain plants (e.g., cotton), resulting in their poor quality for usage. This study serves as demonstration of the novel activity of CADEF1 against the fungus and supports the transgenic strategy to enhance pathogenresistance (Terras et al. 1995; Gao et al. 2000). Additional work is underway to express the defensin in the transgenic plant. It is expected that the Verticillium wilt diseases in cotton should be controlled by this strategy at certain extension. 


\section{References}

Broekaert WF, Terras FRG, Cammue BPA, Vanderleyden J (1990) An automated assay for fungal growth inhibition. FEMS Microbiol Lett 69:55-60

Broekaert WF, Terras FRG, Cammue BPA, Osborn RW (1995) Plant defensins: novel antimicrobial peptides as components of the host defence system. Plant Physiol 108:1353-1358

Broekaert WF, Cammue BPA, De Bolle MFC, Thevissen K, De Samblanx GW, Osborn RW (1997) Antimicrobial peptides from plants. Crit Rev Plant Sci 16:297-323

Chiang CC, Hadwiger LA (1991) The Fusarium solani-induced expression of a pea gene family encoding high cysteine content proteins. Mol Plant-microbe Interact 4:324-331

Do HM, Lee SC, Jung HW, Sohn KH, Hwang BK (2004) Differential expression and in situ localization of a pepper defensin (CADEF1) gene in response to pathogen infection, abiotic elicitors and environmental stress in Capsicum апnиит. Plant Sci 166:12971305

Fang Y, Li X, Yang W (2005) Preliminary evaluations of four actinomyces strains on inhibition against plant pathogenic fungi. J Yunnan Agricult Univ 20:343-345

Frankel S, Sohn R, Leinwand L (1991) The use of sarkosyl in generating soluble protein after bacterial expression. Proc Natl Acad Sci 88:1192-1196

Gao A, Hakimi SM, Mittanck CA, Wu Y, Woerner BM, Stark DM, Shah DM, Liang J, Rommens CMT (2000) Fungal pathogen protection in potato by expression of a plant defensin peptide. Nature Biotechnol 18:1307-1310

Garcia-Olmedo F, Molina A, Alamillo JM, Rodriguez-Palenzuela P (1999) Plant defense peptides. Biopolymers 47:479-491

Hevehan DL, Clark FDB (1997) Oxidative renaturation of lysozyme at high concentration. Biotechnol Bioeng 54:221-230

Lowry OH, Rosebrough NJ, Farr AL, Randall RJ (1951) Protein measurement with the Folin phenol reagent. J Biol Chem 193:265-275
Meyer B, Houlne G, Pozueta-Romero J, Shantz ML, Shantz R (1996) Fruit-specific expression of a defensin-type gene family in bell pepper. Plant Physiol 112:615-622

Sambrook J, Fritsch EF, Maniatis T (1989) Molecular cloning. Cold Spring Harbor, New York, pp 852-897

Sawabe T, Takahasi H, Saeki H, Niwa K, Aono H (2007) Enhanced expression of active recombinant alginate lyase AlyPEEC cloned from a marine bacterium Pseudoalteromonas elyakovii in Escherichia coli by calcium compounds. Enzyme microbial technol 40:285-291

Stiekema WJ, Heidekamp F, Dirkse WG, Van Beckum J, De Haan P, Louwerse JD (1988) Molecular cloning and analysis of four potato tuber mRNAs. Plant Mol Biol 11:255-269

Terras FRG, Eggermont K, Kovaleva V, Raikhel NV, Osborn RW, Kester A, Ress SB, Torrekens F, Van Leuven F, Vanderleyden J, Cammue BPA, Brpelaert WF (1995) Small cysteine-rich antifungal proteins from radish: their role in host defense. Plant Cell 7:573-588

Thomma BPHJ, Cammue BPA, Thevissen K (2002) Plant defensins. Planta 216:193-202

Urdangarin MC, Norero NS, Broekaert WF, de la Canal L (2000) A defensin gene expressed in sunflower inflorescence. Plant Physiol Biochem 38:253-258

Wisniewski ME, Bassett CL, Artlip TS, Webb RP, Janisiewicz WJ, Norelli JL, Goldway M, Droby S (2003) Characterization of a defensin in bark and fruit tissues of peach and antimicrobial activity of a recombinant defensin in the yeast, Pichia pastoris. Physiol Plantarum 119:563-572

Xu H, Reddy ASN (1997) Cloning and expression of a PR5-like protein from Arabidopsis: inhibition of fungal growth by bacterially expressed protein. Plant Mol Biol 34:949-959 